\title{
Spelling of complex nouns with components bio-, eco-, organic-
}

\author{
E. M. Melnikova ${ }^{1}$, A. S. Tomina ${ }^{1}$
}

1Yaroslavl State Pedagogical University named after K. D. Ushinsky, 108/1 Respublikanskaya str., Yaroslavl 150000, Russian Federation

DOI: $10.18255 / 2412-6519-2021-3-334-344$

Research Article

Full text in Russian

The article is devoted to the consideration of the problem of spelling of complex nouns with components bio-, eco-, organic-. It is noted that words with these related roots of foreign language origin, united by synonymous semes 'natural', 'safety', 'utility', are widely used in modern speech. The authors consider the spelling norm in relation to words with these components and the reflection of the norm in real writing practice. The complexity and inconsistency of the spelling rule for spelling complex words leads to the appearance of variants of their spelling and the inconsistency of the usus with the norm. The bio- root, the most mastered, recorded in reference books and spelling dictionaries that require it to be written together with a subsequent part, is presented in the usus not only in continuous, but also in hyphenated and separate design. The same variability is observed for the ecocomponent. The article concludes that these elements significantly expand their compatibility with different bases and receive special semantic emphasis in the text, including with the help of hyphenated and separate spelling. For the organic- component there is no single spelling rule: the foreign language origin of this related component and the consonant base do not solve the issue of a single spelling of words that are considered dictionary. It is noted that the separate design and postposition in relation to the second element of the combination gives this component the status of an application - an unchangeable adjective - in line with the trend towards analyticism in the grammatical system of the modern Russian language.

Keywords: spelling; spelling of complex nouns; continuous spelling; separate spelling; hyphenated spelling; foreign language roots; norm; usus; active processes in Russian

INFORMATION ABOUT THE AUTHORS

$$
\begin{array}{r|l}
\text { Melnikova, Ekaterina M. } & \begin{array}{l}
\text { E-mail: em09@mail.ru } \\
\text { Cand.Sc. (Philology), Associate Professor }
\end{array} \\
\text { Tomina, Anastasia S. } & \begin{array}{l}
\text { E-mail: anastasiya.tomina.1996@mail.ru } \\
\text { Student }
\end{array}
\end{array}
$$

For citation: Melnikova E. M., Tomina A. S. Spelling of complex nouns with components bio-, eco-, organic// Social'nye i gumanitarnye znanija. 2021. Vol. 7, No 3. P. 334-344. (in Russ.)

(C) Melnikova E. M., Tomina A. S., 2021

This is an open access article under the CC BY license (https://creativecommons.org/licenses/by/4.0/) 


\title{
Орфография сложных существительных с компонентами био-, эко-, органик-
}

\author{
Е. М. Мельникова ${ }^{1}$, А. С. Томина ${ }^{1}$
}

1Ярославский государственный педагогический университет им. К. Д. Ушинского, ул. Республиканская, 108/1, Ярославль, 150000, Российская Федерация

DOI: $10.18255 / 2412-6519-2021-3-334-344$

УДК 81’35

Научная статья

Полный текст на русском языке

Статья посвящена рассмотрению проблемы орфографического оформления сложных существительных с компонентами био-, эко-, органик-. Отмечается, что слова с данными связанными корнями иноязычного происхождения, объединяемыми синонимичными семами 'натуральность', 'безопасность', 'полезность', получают в современной речи широкое распространение. Авторы рассматривают орфографическую норму в отношении слов с данными компонентами и отражение нормы в реальной письменной практике. Сложность и противоречивость орфографического правила правописания сложных слов ведёт к появлению вариантов их написания и несоответствию узуса норме. Корень био-, наиболее освоенный, зафиксированный в справочниках и орфографических словарях, требующих его слитного написания с последующей частью, в узусе представлен не только в слитном, но и в дефисном и раздельном оформлении. Такая же вариативность наблюдается и в отношении компонента эко-. В статье делается вывод о том, что данные элементы значительно расширяют свою сочетаемость с разными основами и в тексте получают особое смысловое выделение, в том числе с помощью дефисного и раздельного написания. Для компонента органик- не существует единого орфографического правила: иноязычное происхождение этого связанного компонента и основа на согласный не решают вопроса единого написания слов, которые считаются словарными. Отмечается, что раздельное оформление и постпозиция по отношению ко второму элементу сочетания придаёт данному компоненту статус приложения - неизменяемого прилагательного - в русле тенденции к аналитизму в грамматической системе современного русского языка.

Ключевые слова: орфография, правописание сложных существительных; слитное написание; раздельное написание; дефисное написание; иноязычные корни; норма; узус; активные процессы в русском языке

ИНФОРМАЦИЯ ОБ АВТОРАХ

Мельникова, Екатерина Михайловна (автор для корреспонденции)

Томина, Анастасия Сергеевна
Email:em09@mail.ru ORCID 0000-0002-9795-0971

Кандидат филологических наук, доцент кафедры русского языка

E-mail: anastasiya.tomina.1996@mail.ru

Бакалавр по направлению «Педагогическое

образование» (профиль «Филологическое образование)

Для цитирования: Мельникова Е. М., Томина А. С. Орфография сложных существительных с компонентами био-, эко-, органик- // Социальные и гуманитарные знания. 2021. Том 7, № 2. С. 334-344.

(C) Мельникова Е. М., Томина А. С., 2021

Статья открытого доступа под лицензией СС BY (https://creativecommons.org/licenses/by/4.0/) 
Язык отражает действительность, частью которой становится стремление человека XXI века следить за собственным здоровьем, физической формой - важными составляющими успеха. Продукты питания, содержащие полезные компоненты, предметы обихода, снижающие вероятность аллергии и безопасные для окружающей среды, - это новая реальность современного человека, приводящая к появлению в лексиконе новых слов. Так, в современной речи всё чаще встречаются существительные с компонентами био-, эко-, органик-. Рекламные тексты, надписи на упаковках товаров, призванные привлечь внимание покупателя, включают данные элементы в описание продукта; 'натуральность' и 'безопасность' становятся объединяющими семами, часто приводящими к контекстуальной синонимии в их употреблении.

В данной статье рассмотрены проблемы орфографии имён существительных с компонентами био-, эко-, органик-, приобретающих статус сложного слова, которое в соответствии с правилами может получать слитное, дефисное оформление и, уже на уровне словосочетания, писаться раздельно.

Правила правописания сложных слов - одни из самых противоречивых в русской орфографии. Формулировка многих положений в них далеко не всегда соответствует требованиям к орфографическому правилу, среди которых называются адекватность проблеме, адекватность материалу, логическая непротиворечивость, терминологическая корректность, отсутствие избыточных критериев, достаточная полнота списка исключений [1, с. 124-126].

Трудности кодификации написания сложных имён существительных обусловлены разными причинами. Во-первых, не всегда понятен статус одного из компонентов сложного слова. Если это приставка, то, как известно, приставки пишутся слитно с последующей частью слова, хотя и здесь есть исключения (экс-депymam, cверх-я, cyпер-эго, экстра-класс и др. исключения) [2, с. 74-76]. Если это корень, то важно определение статуса слова - сложное или сложносокращённое: «сложносокращённые существительные пишутся слитно» (за исключением некоторых единичных случаев) [Там же. С. 79-80]; сложные существительные могут писаться по-разному - и слитно, и через дефис. Если один из компонентов является отдельным словом, то речь идёт о словосочетании с приложением и о раздельном написании.

Во-вторых, в основу орфографических правил могут быть положены разные критерии выбора слитного / дефисного / раздельного написания сложного слова, и ни один из них не лишён довольно объёмных списков исключений. Наличие или отсутствие соединительной гласной в сложном имени существительном; характер основы первого компонента (оканчивается на гласный или согласный); склоняемость или несклоняемость компонентов; способность компонентов употребляться в качестве самостоятельного слова; а также «препозиция или постпозиция одной из частей сложного образования; собственный или нарицательный характер имени в составе сложного образования; формальный или семантический повтор основ сложного образования; словообразовательная производность от слов с определённым написанием» [3, с. 58] - данные критерии в своей совокупности учитываются авторами ПАСа («Полного академического справочника» под ред. В. В. Лопатина) [4] и отражаются в РОСе («Русском орфографическом словаре») [5] и в комментировании правил в «Объяснительном русском орфографическом словаре-справочнике» [6], на Орфографическом академическом ресурсе «Академос» [7]. Помимо данных, предлагаются и другие подходы к формулировкам правил. Так, Н. А. Еськова вводит критерий цельнооформленности, по которому «слитно пишутся соединения элементов, 
образующие морфологически цельнооформленные существительные, признаком чего является склонение только второго элемента»; «через дефис пишутся соединения элементов, не обладающие свойством цельнооформленности, соединения, цельнооформленность или нецельнооформленность которых не может быть установлена», а также «цельнооформленные соединения, в первой части которых выступают существительные в именительном падеже с ненулевой флексией» и «соединения, к которым не может быть применён критерий цельнооформленности» [8, с. 63-66]. Несмотря на то, что данные формулировки устраняют многие исключения, как отмечает автор, «предлагаемые правила вносят значительные изменения в то, что принято сейчас» [Там же. С. 67], то есть не соответствуют существующей орфографической норме и предполагают «ломку» сложившейся системы.

Критерии формулировки правил правописания сложных имён прилагательных также разнообразны и противоречивы в реальной практике: среди них называют словообразовательный, семантико-синтаксический, семантический, формально-семантический, функционально-стилистический [9, с. 70], формально-грамматический (учёт суффикса прилагательного в первой части слова) [10]; см. также [11].

Иноязычное происхождение компонентов сложного слова ещё более затрудняет применение правил: «в сфере иноязычной лексики существует довольно большое количество слов, написание которых не подпадает ни под одно правило правописания» [12, с. 224]. Часто норма, представленная в своде действующих правил, «указывается для конкретного слова, а не для всей категории связанных орфографической оппозицией слов в целом ... Пользуясь действующими "Правилами ... ", можно получить конкретные рекомендации по написанию только тех иноязычных слов, которые в них упомянуты в качестве примеров» [Там же. С. 217].

Рассмотрим орфографическое оформление сложных существительных с иноязычными компонентами био-, эко-, органик- в современной письменной речи.

Компонент био-, который называют связанным интернациональным корнем, давно и прочно закрепившийся в русском языке, необходимо писать слитно с последующим словом. В справочнике Д. Э. Розенталя отмечается, что сложные существительные с элементами авто-, агро-, аэро-, био-, вело-, гелио-, гео-, гидро- и др. «независимо от числа названных элементов или других слов в основе» пишутся слитно [13, с. 43]. Новый справочник В. В. Лопатина уточняет данное правило, отмечая иноязычное происхождение подобных элементов и тип основы: слитно пишутся «сложные слова с первой иноязычной (интернациональной) частью, кончающейся на гласную» $[4$, с. 103]. В ПАСе в этом же разделе отмечен и корень эко- (отсутствующий в справочнике Д. Э. Розенталя). Ср. также замечание Е. В. Бешенковой и О. Е. Ивановой о связанном характере данных корней, являющемся одним из критериев слитного написания: «Понятие первой иноязычной части на гласную, с нашей точки зрения, необходимо уточнить таким параметром, как неупотребляемость в качестве отдельного слова. Это позволяет не применять его к словам макси, мини, миди, а также ко многим другим самостоятельным иноязычным словам с финалью на гласную (типа видео, диско, медиа, порно, радио)» [1, с. 178-179]. Таким образом, уточнённое правило имеет следующую формулировку: «Сложные существительные с первой частью, иноязычной по происхождению, оканчивающейся на гласную и самостоятельно не употребляющейся, пишутся слитно» [Там же. С. 179]. 
В реальной речевой практике наблюдаются отступления от данного правила. Био- и эко- могут присоединяться к последующей части с помощью дефиса и даже отделяться пробелом, при этом одно и то же слово получает в разных текстах различное оформление:

- слитное и дефисное:

(1) Биоеда - грибные, ягодные консервы и сушеные грибы (https://www.instagram.com) / био-еда - это здоровые продукты (http://priroda.su/).

(2) Насколько экологична одежда из биохлопка? (https://www.instagram.com/asya.mitskevich/) / Для изготовления нитей используем не обычный, а био-хлопок (https://www.instagram.com/imorganicblog).

(3) Экомолоко «Эконива» цельное (https://www.ekoniva-moloko.com) / Эко-молоко и эко-сыр из молока (https://www.ekoniva-apk.ru/).

(4) Экоприправа фирмы «Эко» / Эко-приправы - уникальные и натуральные жидкие специи (https://www.instagram.com/imorganicblog).

(5) Экошуба в морозы (https://rebbeka.ru) / Эко-шубы: восемь преимуществ и два недостатка (https://www.yapokupayu.ru/blogs).

(6) Особенности ухода за экозамшей (https://romatex.ru) / Эко-замша - достойная альтернатива и правильный выбор (https://popolo4kam.ru).

(7) Плотная холщовая экосумка (http://eco-perenoska.ru) / Эко-сумки, авоськи (https://www.pinterest.ru).

(8) Экостиль в интерьере - особенности и преимущества (https://dizain.guru) / Современный интерьер в эко-стиле: особенности дизайна (https://design-homes.ru).

- слитное и раздельное (часто встречающееся в названии товара и выполняющее, вероятно, функцию смыслового выделения и привлечения внимания покупателя):

(9) Одеяло kariguz биобамбук (https://www.avito.ru) / Подушка бамбуковая «Био Бамбук» (https://www.kariguz.ru).

(10) Сколько служит экокожа на диване? (https://newline-mag.com/) / Рюкзак женский эко кожа (https://yourbox.spb.ru).

- слитное, дефисное и раздельное:

(11) Украинские производители могут войти в сегмент биояблок в Европе (https://latifundist.com) / Био-Яблоки Роял Гала / Купить БИО яблоки (https://fruitymail.ru).

(12) Тонкие носочки для младенцев из $100 \%$ биошерсти, Groedo (https://www.bezhimii.ru) / Недавно купила на пробу 100 \% био-шерсть (органическая шерсть, Германия) (https://www.livemaster.ru) / Наматрасник из овечьей шерсти «Био Шерсть» (http://postela.ru).

(13) Где заказать экоеду в городе ... (https://issuu.com) / Покупайте в интернет магазине Эко-Еда с доставкой по Москве и регионам (https://eco-eda.ru/) / эко еда в Санкт-Петербурге (https://etnoportal.ru/spb).

(14) Где купить экоовощи? (https://lookbio.ru) / Эко-овощи. А зачем? (https://www.1tv.ru) / Эко фрукты и овощи - Сеть овощных баз (https://asktel.ru).

(15) Пекарня «Экохлеб» (https://www.yell.ru) / Эко-Хлеб в России (https://www.product.ru) / Хлебцы Эко хлеб с ядрами семечек (https://dobryankarus.ru). 
Как мы видим, в современной речевой практике расширяется список основ, к которым присоединяются элементы био- и эко- (ср. приводимые в РОСе существительные с био-: биоактиватор, биоакустика, биоархитектура, биоастронавтика, биоатака, биобаланс, биобиблиография, биовентилятор, биоволны, биогаз, биогель, биогельминты, биоген, биогенез и др. - около 185 единиц, среди которых уже фиксируются биойогурт, биокефир, бионаполнитель, биоотходы, биоробот, биотворог [5, с. 49-50]; с эко-: эконегез, экодом, экозащита, экокатастрофа, экокожа, экоконтроль, экология, экомедицина, эконадзор, эконапиток, экопарк, экопитание, экополис, экополитика, экопосёлок, экопродукт, экорегион, экоресурсы, экосад, экосводка, экосистема, экослужба, экосфера, экотип, экотуризм, экоцентр, экоцид, экоэнергетика [Там же. С. 842]). Помимо приведённых примеров, нам встретились следующие новые словоупотребления:

(16) Биоговядина для детского питания (https://ekoniva-apk.ru).

(17) Масло льняное Биолён - инструкция по применению (https://www.lsgeotar.ru).

(18) Экокакао - порошок алкализованный для вас (https://www.elle-craft.ru).

(19) Экомасло детское «Белита-Витэкс» для ухода и массажа (https://irecommend.ru).

(20) Аннотация к книге «ЭКОМЯСО собственного производства. Как избежать ошибок и сэкономить время и деньги. Птица, кролик» (https://www.labirint.ru).

(21) Экосухофрукты из Узбекистана с частных ферм и сушились в тени или насолнце, высоким температурам и обработке серой не подвергались (http://ecociroed.ru).

(22) Голубика - голубая экоягода (http://www.accbud.ua).

Подобная «новизна», своеобразный языковой эксперимент в образовании новых слов становятся, вероятно, одной из причин вариативности написания данных единиц. Кроме того, лингвисты указывают на существование моды на дефисные написания: «В узусе тенденция к употреблению дефиса столь сильна, что встречается дефисное написание даже уже давно освоенных и кодифицированных в слитном написании слов» [1, с. 145-146].

Вариативность написания существительных с компонентом эко- может быть вызвана и двоякой трактовкой сложного слова. Так, краткая формулировка правила в РОСе «эко ... - первая часть сложных слов, пишется слитно» [5, с. 842] в «Объяснительном русском орфографическом словаре-справочнике» дополняется следующим комментарием: «пишется слитно как первая часть сложных существительных, иноязычная по происхождению, оканчивающаяся на гласную и самостоятельно не употребляющаяся или пишется слитно как первая часть сложносокращённых существительных, напр.: экогенез, экозащита, экология, экомедицина, экопитание, экополитика, экоресурсы, экосистема, экосфера, экотехнологии, экоцид ... В современном языке обычно является сокращением слова экологический» [6, с. 486]. Разделительный союз или в данном комментарии указывает на невозможность однозначного определения статуса слова как сложного / сложносокращённого. Е. В.Бешенкова и О.Е.Иванова, рассматривая проблему формального неразличения сложносокращённого слова и сложного слова, состоящего из частей - самостоятельно употребляющихся существительных (спортклуб и джаз-клуб, туроператор и интернет-провайдер, пионервожатый и шеф-повар) - отмечают: «Можно предположить, что решающим фактором в данном случае оказывается закрепившееся написание: 
слитно написанное слово «прочитывается» как сложносокращённое, а написанное с дефисом - как сложное существительное с первой частью, совпадающей с самостоятельным словом» [2, с. 165]. Компонент эко- не употребляется в качестве самостоятельного слова, но наблюдение, сделанное лингвистами в отношении самостоятельных частей-слов, актуально и для таких случаев: дефисные и особенно раздельные написания компонента эко- и даже компонента био-, подкрепляемые выделением их с помощью буквенного регистра (ЭКО овощи, Эко-Хлеб, Эко Хлеб, ЭКО фрукты, БИОЯблоки, БИО яблоки, БИО Шерсть и под.), свидетельствуют, наверное, о некоей дополнительной смысловой нагрузке на данные элементы в сознании пишущих, о представлении их в качестве самостоятельных, полноценных единиц речи. Ср.: экосистема = «экологическая система», но экохлеб/эко-хлеб/эко хлеб - это не совсем «экологический хлеб», а «хлеб, произведённый по экологически безопасным технологиям»: по сведениям Роспотребнадзора, компонент эко- должен указывать на то, что «в ходе производства, транспортировки, хранения, использования или утилизации товара не наносится (или минимизирован) вред для окружающей среды» (http://50.rospotrebnadzor.ru/news). По-новому, видимо, осознаётся компонент биов приведённых выше примерах: его первоначальное предназначение - указание на продукцию переработки молока, обогащённую пробиотиками и/или пребиотиками (ГОСТ Р 52738-2007 «Молоко и продукты переработки молока. Термины и определения»). Присоединение данных компонентов, актуализирующих семы 'полезный', 'безопасный', 'натуральный', к тематически разнообразным основам является маркетинговым приёмом производителей, стимулирующим тем самым покупку товаров (Ср.:

(23) Кофе органик в зернах, или биокофе - это уникальный продукт, при производстве которого производители используют исключительно органические составляющие (поэтому и кофе так называется) (https://www.coffeemag.ru)).

Компонент органик-, относительно недавно появившийся в русской речи, пока не зафиксирован справочниками по правописанию, существительных с ним нет в РОСе и в «Объяснительном русском орфографическом словаре-справочнике». Орфографический академический ресурс «Академос» Института русского языка им. В. В. Виноградова РАН также не комментирует сложные слова с данным элементом (существительное химик-органик не рассматриваем) [7].

Знак «органик» на современных товарах свидетельствует о том, что «органические продукты» произведены «с использованием технологий, обеспечивающих их производство из сырья, полученного без применения пестицидов и других средств защиты растений, химических удобрений, стимуляторов роста и откорма животных, антибиотиков, гормональных и ветеринарных препаратов, ГМО, не подвергнутого обработке с использованием ионизирующего излучения» (СанПиН 2.3.2.2354-08 «Дополнения и изменения № 8 к санитарно-эпидемиологическим правилам СанПиН 2.3.2.1078-01 "Гигиенические требования безопасности и пищевой ценности пищевых продуктов"»).

Национальный корпус русского языка фиксирует употребление компонента органик в составе сложного слова в значении «органический» с 2012 г.:

(24) - Цены на органик-молоко будут примерно в 1, 5 раза выше, то есть продукт будет доступен для людей со средним достатком, - сказал «Известиям» министр сельского хозяйства Ульяновской области Александр Чепухин, подчеркивая, 
что смысл проекта не в низкой стоимости продукта, а в его высоком качестве (М. Казанцева «Moloko Holdings Inc. вложит 8 млрд рублей в российское экомолоко» // Известия, 2012.10.16);

(25) Нуда, на слингах по 8 тысяч никто не делает маркетинг - миллион тканей и расцветок))) органик-фуд туда же, натуральные ткани типа как в мандуке по 5 тыщ - нуя так мимо пробегала (коллективный. Форум: Холивар).

Ср. также употребление компонента органик в качестве постпозитивного определения в 2004 г.:

(26) Только покупай цуккини «органик» (по 2 штуки в пакете продается) (Наши дети: Малыши до года (форум)).

Правила, сформулированные в ПАСе, не предлагают однозначного решения в выборе написания слов с органик- (этот элемент не упоминается). Факторы несклоняемости первого компонента и основы, оканчивающейся на согласный, не являются решающими. Не играет решающей роли в выборе написания и критерий несамостоятельности данного элемента: в п. 2 §121 отмечается, что сложные существительные, первая часть которых встречается только в составе сложных слов, могут писаться и слитно, и через дефис [4, с. 110]. И в целом слова с компонентом органик- попадают, вероятно, в сферу действия правила §121: «Во всех прочих случаях (не охваченных §119-120) слитное или дефисное написание существительных регламентируется в словарном порядке» [Там же. С. 110-111]. То же встречаем в комментарии к правилу в «Объяснительном русском орфографическом словаре-справочнике»: «Написание сложных существительных с не употребляющейся самостоятельно первой частью на согласную определяется по орфографическому словарю» [6, с. 557]. Е. В. Бешенкова и О. Е. Иванова отмечают, что «данная группа слов представляет собой тот фрагмент лексического состава сложных существительных, который орфографически описывается не конкретным правилом в строгом смысле этого слова, а по существу для каждого слова в отдельности» и считают, что определяющими признаками для обращения к словарю являются следующие: «первая часть слова имеет финаль на согласную и отдельно не употребляется» [1, с. 180-181].

В речевой практике существительные с компонентом органик- оформляются по-разному. Встречаются дефисные написания:

(27) Первая органик-водка России «Чистые росы» (https://krasnoeibeloe.ru).

(28) ... Я в ближайшее время поеду на рынок, поддержу не отечественного фермера, а наших братьев с Кавказа - у них хоть может и не органик-фрукты, а выращены под щедрым южным солнцем (https://vegetarian.ru).

Факт недостаточной освоенности данного компонента подтверждается тем, что в речевой практике он может использоваться в написании буквами латиницы:

(29) В составе натурального оrganic-чая исключено наличие усилителей вкуса и запаха, консервантов, ГМО, пестицидов и других вредных соединений (https://teaplace.com.ua).

(30) Чистая вода и organic eдa (https://www.ulitka.com/forum).

Вариативность орфографического оформления сложных слов с компонентом органик- представлена возможностью дефисного и раздельного написания:

(31) органик-еда - это здоровые продукты (https://www.instagram.com/_mamyana) / Органик еда - грибные, ягодные консервы и сушеные грибы (https://www.instagram.com/katrin_ecotrue). 
(32) Органик-одежда из хлопка и конопли (https://www.instagram.com/eco.irk) / Органик одежда «Гринэра» (https://www.instagram.com/imorganicblog).

(33) Производство органик-яиц (https://agrobook.ru) / Органик яйща и сыр: обзор продуктов с экофермы «Алёховщина» (https://m.vk.com).
(34)
Детское
бельё
u3
органик-хлопка

(https://www.instagram.com/asya.mitskevich) / Органик хлопок. Всё лучшее - детям (https://www.babysling.ru).

(35) Indigo Style Органик-шампунь терапевтический без сульфатов и парабенов / Indigo Style органик шампунь цитрусовый без сульфатов и парабенов (https://www.ozon.ru).

(36) Органик-контроль по-европейски (https://agri-news.ru) / Биойогурт Слобода «Органик контроль» - отзывы (https://otzovik.com).

Дефисные написания существительных с элементом органик-, присоединяющимся к тематически разнообразным основам, достаточно частотны в современной практике письма. «В группах слов, написание которых определяется не правилом, а словарём, - отмечают Е. В.Бешенкова и О.Е. Иванова, - регулятором написания, ограничивающим орфографический хаос, зачастую становится влияние ближайшего прецедента. Для сложных слов орфографическим прецедентом является написание слов с той же первой или второй частью. Группы слов с одинаковой первой или второй частью стремятся к единообразному написанию, написанию по аналогии» [5, с. 182]. Возможно, именно дефисные написания с данным компонентом будут кодифицированы. Н. А. Еськова отмечает: «Если проследить за изменениями, которые происходят в написании сложных существительных, они оказываются однонаправленными: дефисные написания заменяются слитными. Когда образования с компонентами типа авиа-, авто- и пр. были «новинками», они чаще писались через дефис. Замена слитными написаниями была сначала стихийной, теперь существует правило» [8, с. 68]. Отразится ли эта тенденция на правописании существительных с компонентом органик-, вопрос спорный. Слитные написания в современной практике не встречаются. Возможно, слитному написанию будут мешать такие факторы, как начальная гласная в основе второй части (*орагникодежда, *органик(ъ)eда), начальная к- последующей основы (*органикконтроль, *органиккрем).

Раздельные написания с компонентом органик- переводят его в статус приложения. Заимствованное аналитическое прилагательное органик, синонимичное, вероятно, прилагательному «органический», активно отражает работу закона экономии речевых средств и в целом усиление аналитизма в грамматической системе русского языка. Выбор между словосочетанием органический кофе и органик кофе / органик-кофе, органическая водка и органик-водка осуществляется в пользу более компактных сочетаний с неизменяемыми прилагательными. Нужно отметить, что та же тенденция просматривается и в отношении сложных слов с компонентами биои эко-: в рекламном тексте слова биояблоки / био-яблоки / био яблоки, эко-магазин, органик-хлопок / органик хлопок и под. явно доминируют над словосочетаниями яблоки БИО-сорта, биоорганические яблоки, магазин полезных и экологически чистых продуктов, органический хлопок.

Как правило, неизменяемое прилагательное находится в постпозиции. Случаи подобного оформления компонентов био-, эко-, органик- также встречаются в практике современного письма:

(37) ПРОДУКТЫ БИО (https://shop.italianweek). 
(38) Ткань эко оптом (https://star-tex.ru).

(39) Молочные продукты ОРГАНИК (https://ryabinki.ru).

«Практика письма, - отмечают Е. В. Бешенкова и О. Е. Иванова, - установила довольно стабильную норму для слов этого типа: за небольшим исключением все неизменяемые постпозитивные определения пишутся раздельно, независимо от того, является это определение определением-приложением или определениемприлагательным: время икс, час пик, величина альфа, птица феникс, брюки клёш, блуза стретч, воротник апаш, юбка гофре, рукав реглан, платье мини, кофе глясе ... » [1, с. 170]. Однако в узусе представлена «вся палитра системных возможностей», поскольку «осознаваемая носителями языка неоднозначность постпозитивных неизменяемых определений приводит и к наличиям колебаний в написании и в стихийном установлении для отдельных слов (словосочетаний) дефисного написания, противоречащего общей тенденции» [Там же. С. 171]. Приведём примеры:

(40) Крем Био для лица увлажняющий для нормальной и комбинированной кожи (https://www.wildberries.ru) / Крем-био для тела облепиховый (https://www.asna.ru).

(41) Indigo, шампунь органик Гиалуроновый (https://cosmetic-sun.ru) / Шампунь-органик Birch SPA для окрашенных волос на березовом соке (https://www.eapteka.ru).

Таким образом, в современной речи, особенно в текстах, создаваемых для продвижения на рынке того или иного продукта, получают активное распространение сложные слова с компонентами био-, эко-, органик-, объединяемыми синонимичными семами 'натуральность', 'безопасность', 'полезность'.

Орфографическое оформление связанных компонентов иноязычного происхождения био-, эко-, органик- в составе сложного имени существительного в современной практике письма вариативно. Несоответствие узуса норме объясняется разными факторами, среди которых важным является сложность и противоречивость орфографического правила. Выбор слитного / дефисного / раздельного написания, основанный на критериях понимания слова как сложного / сложносокращённого / части словосочетания, происхождения первого компонента сложного слова, характера его основы, склоняемости / несклоняемости, свободы / связанности, его позиции по отношению ко второму компоненту и др., приводит к увеличению объёма правила и формированию списков многочисленных исключений.

Степень освоенности иноязычного компонента важна для формирования традиции написания слов, его включающих, и формирования нормы, однако для реальной практики письма она не играет решающей роли. Так, корень био-, наиболее освоенный из рассмотренных иноязычных компонентов, зафиксированный в справочниках и орфографических словарях, требующих его слитного написания с последующей частью, в узусе представлен не только в слитном, но и в дефисном и раздельном оформлении. Такая же вариативность наблюдается и в отношении компонента эко-, описанного в ПАСе. Данные элементы значительно расширяют свою сочетаемость с разными основами и в рекламном тексте получают особое смысловое выделение, в том числе с помощью дефисного и раздельного написания.

Однозначного правила правописания существительных с компонентом органик-, относительно недавно появившимся в русском языке и ещё не зафиксированным в справочниках, не существует: иноязычное происхождение этого связанного компонента и основа на согласный не решают вопроса единого написания слов с ним. 
В практике письма встречаются дефисные и раздельные написания. Раздельное оформление и постпозиция по отношению ко второму элементу сочетания придаёт данному компоненту статус приложения - неизменяемого прилагательного - и отражает тем самым тенденцию к аналитизму в грамматической системе современного русского языка.

\section{Ссылки / References}

1. Бешенкова Е. В., Иванова О. Е. Проблемы нормы и кодификации правописания сложных существительных // Труды Института русского языка им. В. В. Виноградова. 2014. № 1. C. 119-199.

2. Бешенкова Е. В., Иванова О. Е. Правила русской орфографии с комментариями. Тамбов: ТОГОАУ ДПО «Институт повышения квалификации работников образования», 2012. 187 c.

3. Бешенкова Е. В., Иванова О. Е. Сложные существительные и сочетания с приложениями как объект орфографического описания // Русский язык в научном освещении. 2010. № 2 (20). C. 57-76.

4. Правила русской орфографии и пунктуации. Полный академический справочник / Под ред. В. В. Лопатина. М.: АСТ-ПРЕСС КНИГА, 2009. 432 с.

5. Русский орфографический словарь: около 200000 слов / Под ред. В. В. Лопатина, О. Е. Ивановой. М.: АСТ-ПРЕСС КНИГА, 2016. 896 с.

6. Объяснительный русский орфографический словарь-справочник / Ин-т рус. языка им. В. В. Виноградова; Е. В. Бешенкова (отв. ред.), О. Е. Иванова, Л. К. Чельцова. М.: АСТПРЕСС КНИГА, 2015. 592 с.

7. Орфографический академический ресурс «АКАДЕМОС». URL: http://orfo.ruslang.ru/ (дата обращения: 23.07.2021).

8. Еськова Н. А. Слитные / дефисные написания существительных и цельнооформленность слова // Лингвистические основы кодификации русской орфографии: теория и практика / Под ред. В. В. Лопатина. М.: Азбуковник, 2009. С. 59-68.

9. Сидорова Е. Г. Проблемы и противоречия кодификации сложных прилагательных в русском языке // Вестник ВолГУ. Серия 2. Языкознание. 2018. Т. 17. № 4. С. 68-80.

10. Букчина Б. З., Калакуцкая Л. П. Слитно или раздельно? Опыт словаря-справочника. М.: Русский язык, 1983. 879 с.

11. Борунова С. Н. О написании сложных прилагательных в русском языке. Из истории кодификации // Лингвистические основы кодификации русской орфографии: теория и практика / Под ред. В. В. Лопатина. М.: Азбуковник, 2009. С. 73-99.

12. Нечаева И. В. Проблемы орфографической кодификации иноязычных заимствований // Лингвистические основы кодификации русской орфографии: теория и практика / Под ред. В. В. Лопатина. М.: Азбуковник, 2009. С. 213-239.

13. Розенталь Д. Э. Справочник по правописанию и литературной правке / Под ред. И. Б. Голуб. М.: Айрис-пресс, 2008. 368 с. 